\title{
Komunikasi pada saat handover memengaruhi pelaksanaan indikator patient safety
}

\author{
Afip Saefulloh ${ }^{1}$, Aria Pranatha ${ }^{2}$, Rany Mulyani ${ }^{3}$ \\ ${ }^{1}$ RSUD Gunung Jati Cirebon \\ ${ }^{2,3}$ Stikes Kuningan \\ *Coresponding Author: ners.ariap79@gmail.com
}

\begin{abstract}
Abstrak
Pendahuluan: Komunikasi dengan menggunakan SBAR pada saat handover merupakan salah satu upaya dalam menjaga keselamatan pasien. Penelitian ini untuk mengetahui hubungan komunikasi pada saat handover dengan pelaksanaan indikator patient safety. Metode: Penelitian ini menggunakan analitik kuantitatif dengan pendekatan penelitian cross sectional. Responden penelitian sebanyak 35 perawat dengan teknik accidental sampling. Pengukuran variabel melalui lembar observasi. Uji statistik menggunakan uji korelasi non parametrik dengan menggunakan rumus Rank Spearman. Hasil: Penelitian menunjukkan bahwa dari 35 responden perawat 12 perawat $(34,3 \%)$ mempunyai tingkat komunikasi SBAR yang kurang, 11 perawat $(31,4 \%)$ cukup dan 12 perawat $(34,3 \%)$ baik. Lebih dari separuhnya tidak melaksanakan indikator patient safety $(54,3 \%)$. Adapun Nilai $p$ value $=0,000$ dan nilai rho 0,867 . Simpulan: Ada hubungan yang signifikan antara komunikasi pada saat handover dengan pelaksanaan indikator patient safety. Rumah sakit dan perawat diharapkan agar lebih meningkatkan kualitas pelayanan keperawatan terutama dalam penerapan komunikasi efektif berbasis SBAR sesuai dengan SPO yang berlaku.
\end{abstract}

Kata kunci: Komunikasi SBAR; handover; indikator patient safety

The relationship of communication at handover with implementation patient safety indicators

\begin{abstract}
Introduction: Communication using SBAR at the time of delivery was an effort to maintain patient safety. Purposes: This study was to see the relationship between communication at the time of delivery and the implementation of patient safety indicators. Methods: This study used quantitative analytic with a cross sectional research approach. Research respondents were 35 nurses with accidental sampling technique. Measurement variables through the observation sheet. Statistical test using nonparametric trials using the Rank Spearman formula. Results: The study showed that of the 35 respondent nurses 12 nurses (34,3\%) had a low level of SBAR communication, 11 nurses (31,4\%) were sufficient and 12 nurses (34,3\%) were good. More than half did not implement patient safety indicators $(54,3 \%)$. The $p$ value $=0,000$ and the rho value 0,867. Conclusions: There is a significant relationship between communication at handover and the implementation of patient safety indicators. Hospitals and nurses are expected to further improve the quality of nursing services, especially in the effective implementation of SBAR-based in accordance with the applicable SPO.
\end{abstract}

Keywords: SBAR communicatio; handover; patient safety indicators

How to Cite: Saefulloh, A., Pranatha, A., \& Mulyani, R. (2020). Hubungan komunikasi pada saat handover dengan pelaksanaan indikator patient safety. NURSCOPE: Jurnal Penelitian dan Pemikiran IImiah Keperawatan, 6(1), 27-33 


\section{PENDAHULUAN}

Komunikasi yang efektif dalam pelaksanaan pemberian asuhan keperawatan profesional merupakan unsur utama bagi perawat untuk mencapai hasil yang optimal dalam kegiatan keperawatan. Komunikasi yang efektif dalam pelayanan keperawatan membutuhkan pengetahuan, keterampilan dan empati. Begitupula dalam mengaplikasikan komunikasi yang efektif maka perawat harus mengetahui kapan harus berbicara, apa yang harus dikatakan dan bagaimana mengatakan-nya serta memiliki kepercayaan diri (Suhriana, 2012).

Kompetensi profesional dalam praktek keperawatan tidak hanya psikomotor dan keterampilan diagnostik klinis, tetapi juga kemampuan dalam keterampilan interpersonal dan komunikasi. Kerjasama tim yang baik dapat membantu mengurangi masalah patient safety, sehingga kesalahan (error) $70-80 \%$ yang disebabkn oleh buruknya komunikasi dan pemahaman dalam tim dapat diminimalisir. Berdasarkan penelitian yang telah dilakukan oleh Yulistiana (2012) di salah satu RS Swasta di Surabaya pada tingkat pengkajian yang dilakukan kepada perawat pelaksana mengenai pengalaman komunikasi perawat melalui pengisian kuesioner pada tahun 2009 didapatkan pengalaman komunikasi dalam keperawatan $58,7 \%$ dan $41,3 \%$. Persentase tersebut menunjukkan komunikasi antara sesama perawat maupun dengan atasan dalam pelayanan keperawatan masih perlu ditingkatkan. Masalah komunikasi yang dirasakan antara lain kesalahpahaman dalam menerima informasi.

Begitupula hal tersebut didukung penelitian yang dilakukan Catherine (2016) di Denver Health Medical Center yang mengemukakan bahwa salah satu penyebab kegagalan komunikasi perawat dalam melakukan operan antar shift $30 \%$ disebabkan karena kegagalan komunikasi secara langsung seperti: komunikasi yang terlambat, kegagalan komunikasi dengan semua anggota tim keperawatan, isi komunikasi yang tidak jelas. Berdasarkan data insiden keselamatan pasien di Kota Cirebon pada tahun 2018 didapatkan beberapa indikator keselamatan masih belum mencapai target, seperti pada ketepatan identifikasi pasien capaiannya $95,7 \%$ dengan target $100 \%$ dan komunikasi efektif capaiannya $44,3 \%$ dengan target $100 \%$ serta adanya 1 kasus yang terjadi pada pengurangan risiko pasien jatuh. Sedangkan, data insiden keselamatan pasien pada tahun 2018 di Kota Cirebon didapatkan angka kejadian pasien jatuh 0,18\% dengan standarnya $0 \%$, angka kejadian cedera akibat restrain 0,49\% dengan standarnya 0\% (Rumah Sakit Gunung Jati Cirebon, 2019).

Rumah Sakit Gunung Jati Cirebon merupakan rumah sakit tipe B yang menjadi salah satu rumah sakit rujukan dari puskesmas di wilayah Kota Cirebon. Data Insiden Keselamatan Pasien (IKP) yang didapatkan dari Tim Keselamatan Pasien RSD Gunung Jati Cirebon mengalami peningkatan dari 18 kasus menjadi 27 kasus (2017-2018) dan pada tahun 2018 ditemukan insiden keselamatan pasien yaitu sebanyak 27 kasus yang mana 14 kasus diantaranya disebabkan oleh kelalaian perawat, antara lain pasien jatuh ( 2 kasus), salah injeksi obat (4 kasus), salah identifikasi pasien saat pengambilan darah (3 kasus), dan salah dokumentasi pasien operasi ( 5 kasus). Data ini memberikan gambaran bahwa masih adanya masalah keselamatan pasien mengingat insiden KTD di rumah sakit diharapkan berada pada nilai zero defect (tingkat insidensi 0\%) (RSD Gunung Jati Cirebon, 2019).

Komunikasi yang tidak efektif merupakan salah satu faktor yang menjadi penyebab permasalahan yang terjadi pada patient safety. Menurut Virawan (2012) Salah satu upaya untuk mengatasi permasalahan tersebut yaitu dengan meningkatkan sistem komunikasi SBAR (Situation, Background, Assesement, Recomendation) agar dapat berfungsi sebagai alat untuk standarisasi komunikasi antara perawat dengan perawat maupun perawat dengan dokter. Hasil penelitian yang dilakukan menunjukkan bahwa SBAR dapat membantu dalam pengembangan skema yang memungkinkan membuat keputusan yang cepat oleh perawat. Komunikasi SBAR adalah komunikasi dengan menggunakan alat yang logis untuk mengatur informasi sehingga dapat ditransfer kepada 
orang lain secara akurat dan efisien. Komunikasi dengan menggunakan alat terstruktur SBAR untuk mencapai ketrampilan berfikir kritis dan menghemat waktu.

Pelaksanaan komunikasi SBAR pada saat hand over jika dilaksanakan sesuai dengan Standard Operational Procedure (SOP) akan berdampak menjadi komunikasi efektif di Rumah Sakit, sehingga komunikasi SBAR tersebut dapat digunakan pada saat melakukan handover pasien atau handover perawat, melaporkan kondisi pasien kepada dokter penanggung jawab pasien serta dapat digunakan juga dengan metode Tulis, Baca, Konfirmasi kembali (TBaK) yang dilakukan pada saat menerima instruksi dari dokter, saat menerima tes kritis (critical test), dan saat menerima nilai kritis dari laboratorium/radiologi. Penerapan Standard Operational Procedure (SOP) dalam setiap tindakan perawat dengan menggunakan komunikasi SBAR pada saat handover antar perawat merupakan salah satu upaya dalam menjaga keselamatan pasien/patient safety.

Sasaran patient safety yang tertuang dalam PMK No. 1691/MENKES/PER/ VIII/2011 dibuat dengan mengacu pada sembilan solusi keselamatan pasien oleh WHO bertujuan untuk mendorong perbaikan spesifik dalam keselamatan pasien. Handover pasien termasuk pada sasaran yang kedua, yaitu peningkatan komunikasi yang efektif. Keakuratan data yang diberikan saat handover sangat penting, karena dengan handover ini maka pelayanan asuhan keperawatan yang diberikan akan bisa dilaksanakan secara berkelanjutan, dan mewujudkan tanggungjawab dan tanggunggugat dari seorang perawat. Bila handover tidak dilakukan dengan baik, maka akan muncul kerancuan dari tindakan keperawatan yang diberikan karena tidak adanya informasi yang bisa digunakan sebagai dasar pemberian tindakan keperawatan. Hal ini akan menimbulkan kejadian yang tidak diinginkan (KTD) yang merupakan salah satu kejadian yang melanggar dari prinsip keselamatan pasien (Patient Safety) (Cahyono, 2012).

Pelaksanaan komunikasi pada saat handover di Ruang Rawat Inap Bedah Rumah Sakit Daerah Gunung Jati Cirebon diberlakukan sejak rumah sakit berdiri tetapi dalam pelaksanaannya belum mencapai target $100 \%$. Peneliti melakukan studi pendahuluan didapatkan hasil pengumpulan data kepatuhan menggunakan komunikasi efektif antar shift atau pada saat handover pasien belum mencapai standard dengan rata-rata pencapaian pada tahun 2017 untuk masing-masing indikator SBAR 73,79 \%, TbaK (tulis, baca, konfirmasi kembali) 22,23\% dan tanda tangan dokter 32,84\%. (Ruang Rawat Inap Bedah Rumah Sakit Daerah Gunung Jati Cirebon, 2018).

Hasil studi pendahuluan yang dilakukan peneliti di Rumah Sakit Daerah Gunung Jati Cirebon, diperoleh hasil bahwa kegiatan handover yang dilakukan belum optimal, informasi yang disampaikan belum akurat dimana perawat hanya menyebutkan nama pasien dan tindakan yang telah dilakukan tanpa menjelaskan apa yang melatar belakangi keluhan pasien dan rencana tindakan lanjut yang harus di lakukan, dan ketika ditanya pada 6 orang perawat bagaimana melakukan handover yang benar, mereka mengatakan tidak tahu dan tidak bisa menjelaskan betapa pentingnya informasi yang akurat melalui komunikasi dalam pelaksanaan handover.

Berdasarkan hasil studi pendahuluan terdapat kejadian yang berdampak pada patient safety yaitu pada saat pasien masuk diinstruksikan untuk dilakukan pemeriksaan cek GDS namun ketika handover instruksi ini tidak disampaikan sehingga pasien gelisah dan dilakukan cek GDS ternyata hasil GDS rendah. Kasus lainnya yang disebabkan karena komunikasi handover antar shift tidak mematuhi SOP SBAR yaitu instruksi dokter yang tidak dioverkan sehingga cairan infus pada pasien tertentu yang seharusnya sudah diganti menjadi D10 namun tetap dengan cairan infus NS. Dan kasus yang paling sering terjadi adalah kerja long shift perawat (sore-malam) membuat perawat lainnya mengandalkan perawat yang long shift tersebut, beranggapan bahwa perawat tersebut lebih mengetahuai keadaan pasien padahal perawat tersebut dalam kondisi kelelahan sehingga komunikasi SBAR tidak mematuhi SOP yang seharusnya dan berdampak pada keselamatan pasien. 
Penelitian ini bertujuan untuk mengetahui "Hubungan komunikasi pada saat handover dengan pelaksanaan indikator patient safety di Instalasi Rawat Inap Rumah Sakit Daerah Gunung Jati Kota Cirebon Tahun 2019".

\section{METODE}

Jenis penelitian dalam penelitian ini menggunakan analitik kuantitatif dengan pendekatan penelitian menggunakan pendekatan cross sectional. Populasi pada penelitian ini adalah seluruh perawat yang ada di Instalasi Rawat Inap Bedah Rumah Sakit Daerah Gunung Jati Kota Cirebon sebanyak 36 orang. Dalam analisa bivariat ini yang akan dianalisis hubungan stres kerja dengan kinerja perawat pelaksana. Variabel dalam penelitian ini menggunakan skala ordinal dan ordinal, maka uji statistik yang digunakan dalam penelitian ini menggunakan uji korelasi non parametrik dengan menggunakan rumus Rank Spearman.

\section{HASIL DAN PEMBAHASAN}

Berdasarkan pengumpulan data yang telah dilakukan dari bulan Mei-Juli 2019 dari 36 responden hanya 35 responden yang didaptkan dikerenakn 1 orang sedang cuti melahirkan. Adapun hasil sebagai berikut :

Tabel 1. Hubungan komunikasi pada saat handover dengan pelaksanaan indicator patient safety di instalasi rawat inap bedah rumah sakit Daerah Gunung Jati Kota Cirebon Tahun 2019

\begin{tabular}{lcccc}
\hline Tingkat Komunikasi SBAR & Frekuensi (f) & Prosentase (\%) & Nilai P Value & Nilai Rho \\
\hline Kurang & 11 & 31,4 & & \\
\cline { 1 - 3 } Cukup & 9 & \multirow{2}{*}{0,000} & \multirow{2}{*}{0,867} \\
\cline { 1 - 3 } Baik & 15 & 25,7 & & \\
\cline { 1 - 3 } & 35 & 100 & & \\
\hline
\end{tabular}

Tabel 1 menunjukkan bahwa tingkat komunikasi pada saat handover hampir setengahnya $(42,9)$ dengan kategori baik. Selain itu, ada hubungan yang signifikan antara komunikasi pada saat handover dengan pelaksanaan indikator patient safety di Instalasi Rawat Inap Bedah Rumah Sakit Daerah Gunung Jati Kota Cirebon tahun 2019 dengan $p$ value= 0,000 dan nilai rho 0,867, artinya tingkat kekuatan hubungan (korelasi) antara variabel komunikasi pada saat handover dengan variabel pelaksanaan indikator patient safety dengan kriteria kuat

Gambaran komunikasi pada saat handover di Instalasi Rawat Inap Bedah Rumah Sakit Daerah Gunung Jati Kota Cirebon Tahun 2019 kurang dari setengahnya perawat pelaksana yang melakukan handover dengan tingkat komunikasi SBAR yang baik dimana komunikasi tersebut sesuai dengan aturan komunikasi SBAR yang seharusnya dilakukan oleh perawat pada saat handover. Namun demikian, ada pula perawat pelaksana yang melakukan handover dengan tingkat komunikasi SBAR yang baik.

Pelaksanaan komunikasi SBAR yang kurang pada saat handover dilakukan pada penelitian ini dimungkinkan karena beban kerja yang tinggi bagi perawat yang sedang berdinas, pada saat berdinas perawat hanya berdua dengan jumlah pasien yang penuh (Full Bed), sehingga perawat sudah lelah dan komunikasi yang dilakukan pada saat handover juga akhirnya tidak optimal. Perawat yang melakukan komunikasi SBAR yang baik pada saat handover dimungkinkan karena perawat mempunyai latar belakang pendidikan yang tinggi sehingga menyadari pentingnya komunikasi SBAR pada saat handover.

Komunikasi efektif merupakan salah satu sasaran keselamatan pasien. Situation, Background, Assesment, dan Recomendation (SBAR) merupakan komunikasi efektif yang banyak diadopsi di dunia internasional. SBAR dapat digunakan dalam berkomunikasi praprosedur yang akan dilakukan ke 
pasien, selama handover, atau setiap saat ada perubahan yang tak terduga dalam perawatan pasien (Haig, Sutton, \& Whittington, 2016). Hingga saat ini, hampir semua RS di Indonesia mengimplementasikan komunikasi SBAR.

Penelitian ini sejalan dengan penelitian yang dilakukan oleh Kusumapradja (2019) mengatakan bahwa $66 \%$ sentinel events yang dilaporkan disebabkan oleh permasalahan komunikasi, terutama komunikasi saat Handover dan diketahui bahwa komunikasi pada saat handover masih kurang (45\%). Berdasarkan hasil penelitian maka peneliti berasumsi bahwa komunikasi dapat meningkatkan kerjasama antara perawat, dokter, dan kepuasan pasien serta meningkatkan keselamatan pasien dengan membangun kerja sama tim dan hubungan kerja yang positif. Gambaran Pelaksanaan Indikator Patient Safety di instalasi rawat inap bedah Rumah Sakit Daerah Gunung Jati Kota Cirebon tahun 2019 sebagian besar perawat pelaksana di Rumah Sakit Daerah Gunung Jati Kota Cirebon belum melaksanakan indikator patient safety dalam memberikan asuhan keperawatan pada pasien.

Pada penelitian ini perawat yang tidak melaksanakan indikator patient safety dimungkinkan karena perawat kurang memiliki kesadaran dalam mengenali situasi bahwa situasi tersebut akan mengancam keselamatan pasien serta mengabaikan informasi klinis penting terkait keselamatan pasien. Keselamatan pasien memiliki enam sasaran yang salah satunya adalah meningkatkan komunikasi efektif. Insiden keselamatan pasien merupakan kejadian yang memberikan dampak buruk kepada pasien baik langsung maupun tidak langsung. Dampak langsung dari insiden keselamatan pasien dapat menimbulkan kecacatan, cidera, bahkan kematian. Dampak tidak langsung dari insiden keselamatan pasien adalah lama hari rawat memanjang diikuti dengan biaya perawatan yang meningkat.

Berdasarkan hasil penelitian ini maka peneliti berpendapat bahwa keselamatan pasien merupakan dasar dalam pelayanan kesehatan dan seyogyanya menyatu dengan pengobatan dan perawatan itu sendiri. Pasien memiliki risiko terhadap setiap tindakan pengobatan dan perawatan yang diterimanya sehingga, program utama patient safety, yaitu suatu usaha untuk menurunkan angka kejadian tidak diharapkan (KTD) yang sering terjadi pada pasien selama dirawat di rumah sakit yang dapat merugikan baik pasien maupun pihak rumah sakit.

Hubungan Komunikasi pada Saat Handover dengan Pelaksanaan Indikator Patient Safety di Instalasi Rawat Inap Bedah Rumah Sakit Daerah Gunung Jati Kota Cirebon Terdapat hubungan yang signifikan antara komunikasi pada saat handover dengan pelaksanaan indikator patient safety di Instalasi Rawat Inap Bedah Rumah Sakit Daerah Gunung Jati Kota Cirebon tahun 2019, yang dibuktikan dengan $p$ value $=0,000$. Hasil penelitian ini memperoleh nilai Correlation Coefficient sebesar 0,867, artinya tingkat kekuatan hubungan (korelasi) antara variabel komunikasi pada saat handover dengan variabel pelaksanaan indikator patient safety adalah sebesar 0,867 atau kekuatan yang kuat. Angka korelasi bernilai positif, yaitu 0,867 sehingga hubungan kedua variabel bersifat searah dengan demikian diartikan bahwa semakin baik komunikasi SBAR yang dilakukan perawat pada saat handover maka semakin tinggi penerapan pelaksanaan indikator patient safety yang dilakukan perawat.

Transfer informasi pada saat pergantian shift dari perawat yang jaga sebelumnya ke perawat yang akan melanjutkan shift berikutnya disebut dengan handover. Handover ini merupakan salah satu kegiatan professional relationshif dalam lingkup pelayanan keperawatan yang bertujuan untuk menyampaikan informasi dari setiap pergantian shift serta memastikan efektifitas dan keamanan dalam perawatan pasien. Adapun hal yang disampaikan pada saat handover yaitu informasi terkait dengan keadaan klinis pasien, kebutuhan pasien, keadaan personal pasien, sampai pada faktor sosial pasien. 
Hasil penelitian ini didukung oleh penelitian Sammer \& James (2017) bahwa komunikasi SBAR menjadi salah satu faktor yang dapat mempengaruhi keselamatan pasien. Komunikasi SBAR yang diterapkan dengan baik maka dapat meningkatkan kerjasama antara perawat, dokter, dan meningkatkan kepuasan serta keselamatan pasien. Komunikasi SBAR dapat membangun kerja sama tim yang baik dan hubungan kerja yang positif (Boyle \& Kochinda, 2014). Elisabet (2018) menyatakan bahwa baik buruknya pelaksanaan handover ditunjang dengan adanya Standar Operasional Prosedur (SOP) yang harus mencerminkan $4 \mathrm{~W}+1 \mathrm{H}$ (what, who, when, where, how) sehingga dapat dapat memberikan informasi informasi secara cepat dan akurat tentang kondisi pasien dan proses keperawatan yang diberikan.

Hal ini didukung dengan penelitian Kamil (2018) mengemukakan bahwa handover yang tidak efektif dapat berkontribusi terhadap kesalahan dan pelanggaran dalam keselamatan perawatan pasien, termasuk kesalahan pengobatan, salah operasi, dan kematian pasien. Sedangkan menurut Alvarado et all (2016) bahwa komunikasi yang diberikan perawat dalam pertukaran shift (operan) sangat membantu dalam perawatan pasien dan buruknya komunikasi dapat mengakibatkan kematian atau cedera yang serius di rumah sakit. Handover yang tidak berjalan dengan baik dapat mempengaruhi perawatan. Menurut penelitian yang dilakukan oleh Hughes (2008) dalam Kamil (2018) mengungkapkan bahwa faktor pelaksanaan handover tidak berjalan dengan baik disebabkan oleh faktor eksternal dan internal individu dan organisasi.

Berdasarkan hasil penelitian maka peneliti berpendapat untuk meminimalisir dampak yang dapat merugikan baik bagi pasien maupun rumah sakit, maka sangat diperlukan peningkatan keterampilan perawat dalam pelaksanaan komunikasi efektif SBAR. Program keselamatan pasien di rumah sakit meliputi pengidentifikasian pasien, komunikasi efektif pada saat timbang terima, menghindari kesalahan pemberian obat, meniadakan kesalahan prosedur tindakan, mencegah infeksi nosokomial, serta pencegahan pasien jatuh. Apabila komunikasi yang dilaksanakan dengan efektif pada saat handover tentunya dapat meningkatkan kualitas pelayanan keperawatan di rumah sakit.

\section{SIMPULAN DAN SARAN}

Terdapat hubungan yang signifikan antara komunikasi pada saat handover dengan pelaksanaan indikator patient safety di Instalasi Rawat Inap Bedah Rumah Sakit Daerah Gunung Jati Kota Cirebon Tahun 2019. ( $p$ value : $0,000<\alpha: 0,05$ ) dengan kekuatan hubungan yang kuat ( $r h o=0,867$ ). Peneliti memberikan saran kepada pihak Rumah Sakit Daerah Gunung Jati Cirebon untuk melakukan monitoring dan evaluasi terhadap pelaksanaan komunikasi efektif SBAR sehingga kualitas pelayanan keperawatan dapat meningkat terutama dalam penerapan komunikasi efektif berbasis SBAR sesuai dengan SPO yang berlaku.

\section{DAFTAR PUSTAKA}

Alvarado, K., Lee, R., Christoffersen, E., Fram, N., Boblin, S., Poole, N. \& Forsyth, S.(2016). Transfer of accountability: transforming shift handover to enhance patient safety. Healthcare Quarterly, (Sp). Diakses dari website http://www.ihffih.org/content/download/1350/13051 /file/Clinical\%20Handover\%20system\%20change,\%20leadership\%20and\%20principles.pdf. diakses pada tanggal 20 Juni 2019.

Arikunto,S. (2017). Prosedur Penelitian. Jakarta:Rineka Cipta. Cahyono, (2012). Manajemen Sumber Daya Manusia. Yogyakarta.

Elisabet. (2018). Optimalisasi pelaksanaan handover berdasarkan standar national patient safety. Jurnal Administrasi dan Kebijakan Kesehatan, 6:166-171. Diakses pada tanggal 24 Juni 2019. 
Effendy, O. (2016). Ilmu Komunikasi: Teori dan Prakteknya, Bandung : Remaja Rosdakarya. Hamzah. (2008). Identifikasi Pasien. Jakarta : Bumi Aksara.

Heriana, C. (2015). Manajemen Pengolahan Data Kesehatan. Bandung: Refika Aditama.

Hughes, R.G. (2012). Patient Safety and Quality: An Evidence-Based Handbook for Nurses, agency for Healthcare Research and Quality U.S. Department of Health and Human Services, 540 Gaither Road Rockville, MD 20850.

Kamil, H. (2018). Handover dalam pelayanan keperawatan. 4(11), 102-116.

Kusumapradja, R. (2019). Patient safety in nursing. Makalah seminar. Tidak dipublikasikan.

Joint Commission International (JCl). (2013). Accreditation Standards for Hospitals. Retrieved from Joint Commission International: Artikel Kesehatan diakses dari http://www.jointcommissioninternational.org/ diakses pada tanggal 15 Maret 2019.

Kerr, M. P. (2012). A Qualitative Study of Shift Hand Over Practice and Function from a Socio Technical. Journal of advance nursing, 37(2) 125-134.

Kementerian Kesehatan RI. (2017). Profil Kesehatan Indonesia 2016. Jakarta: Kementrian Kesehatan RI, 2017.

Ni Nyoman Sudresti. (2015). Hubungan Penggunaan Metode Komunikasi SBAR dengan Kualitas Pelaksanaan Bedside Handover Di Ruang Ratna RSUP Sanglah Denpasar. Jurnal Penelitian keperawatan. Diakses pada tanggal 10 April 2019 Diakses dari http://web.ebscohost.com/ehost/resultadvaanced.

Nursalam. (2017). Manajemen keperawatan: Aplikasi dalam praktik keperawatan profesional. Edisi 4. Jakarta: Salemba Medika.

Rofii, M. (2015). Komunikasi efektif dengan SBAR di RSUD Tugurejo Semarang. Jurnal Keperawatan. Diakses pada tanggal 10 April 2019 dari http://web.ebscohost.com/ehost/resultadvaanced?

Robbins and Stephen. (2013). 10 Prinsip Kepuasan Pelanggan. Jakarta: PT. Elex Media Komputindo

Rumah Sakit Gunung Jati Kota Cirebon. (2018). Profil Rumah Sakit Gunung Jati. Cirebon: RSGJ. Jakarta: EGC.

Sammer, C. E \& James, B. R. (2017). Patient safety culture: The nursing unit leader's role. Online Journal of Issues in nursing, 16(3), 8-3. from http://search.proquest.com/ docview/103500569?accountid=17242. Diakses tanggal 03 Juli 2019.

Virawan. (2012). Faktor-Faktor yang Mempengaruhi Kepatuhan Staf Perawat Menggunakan Enam Benar dalam Menurunkan Kasus Pasien Safety di Rumah Sakit Surya Husada. Skripsi Diakses tanggal 03 Februari 2019. 